
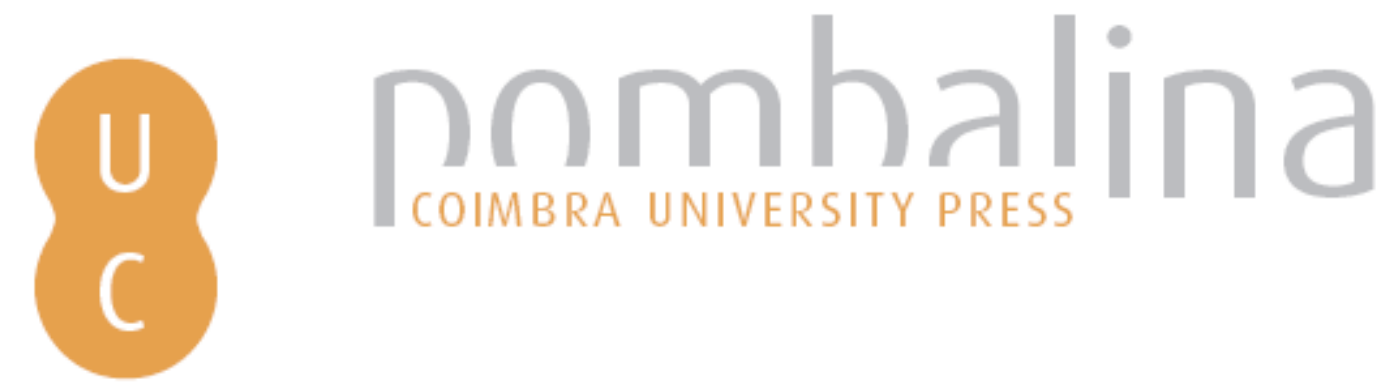

\title{
A figura de Catarina de Ataíde na peça radiofónica de Günter Eich Die Brandung Vor Setubal e na novela Tod Des Dichters de Ludwing Tieck
}

Autor(es): $\quad$ Garraio, Júlia

Publicado por: Imprensa da Universidade de Coimbra

URL

persistente: URI:http://hdl.handle.net/10316.2/31153

DOI: $\quad$ DOI:http://dx.doi.org/10.14195/978-989-26-0569-2_31

Accessed : $\quad$ 26-Apr-2023 04:43:51

A navegação consulta e descarregamento dos títulos inseridos nas Bibliotecas Digitais UC Digitalis, UC Pombalina e UC Impactum, pressupõem a aceitação plena e sem reservas dos Termos e Condições de Uso destas Bibliotecas Digitais, disponíveis em https://digitalis.uc.pt/pt-pt/termos.

Conforme exposto nos referidos Termos e Condições de Uso, o descarregamento de títulos de acesso restrito requer uma licença válida de autorização devendo o utilizador aceder ao(s) documento(s) a partir de um endereço de IP da instituição detentora da supramencionada licença.

Ao utilizador é apenas permitido o descarregamento para uso pessoal, pelo que o emprego do(s) título(s) descarregado(s) para outro fim, designadamente comercial, carece de autorização do respetivo autor ou editor da obra.

Na medida em que todas as obras da UC Digitalis se encontram protegidas pelo Código do Direito de Autor e Direitos Conexos e demais legislação aplicável, toda a cópia, parcial ou total, deste documento, nos casos em que é legalmente admitida, deverá conter ou fazer-se acompanhar por este aviso.

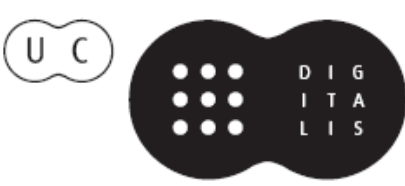




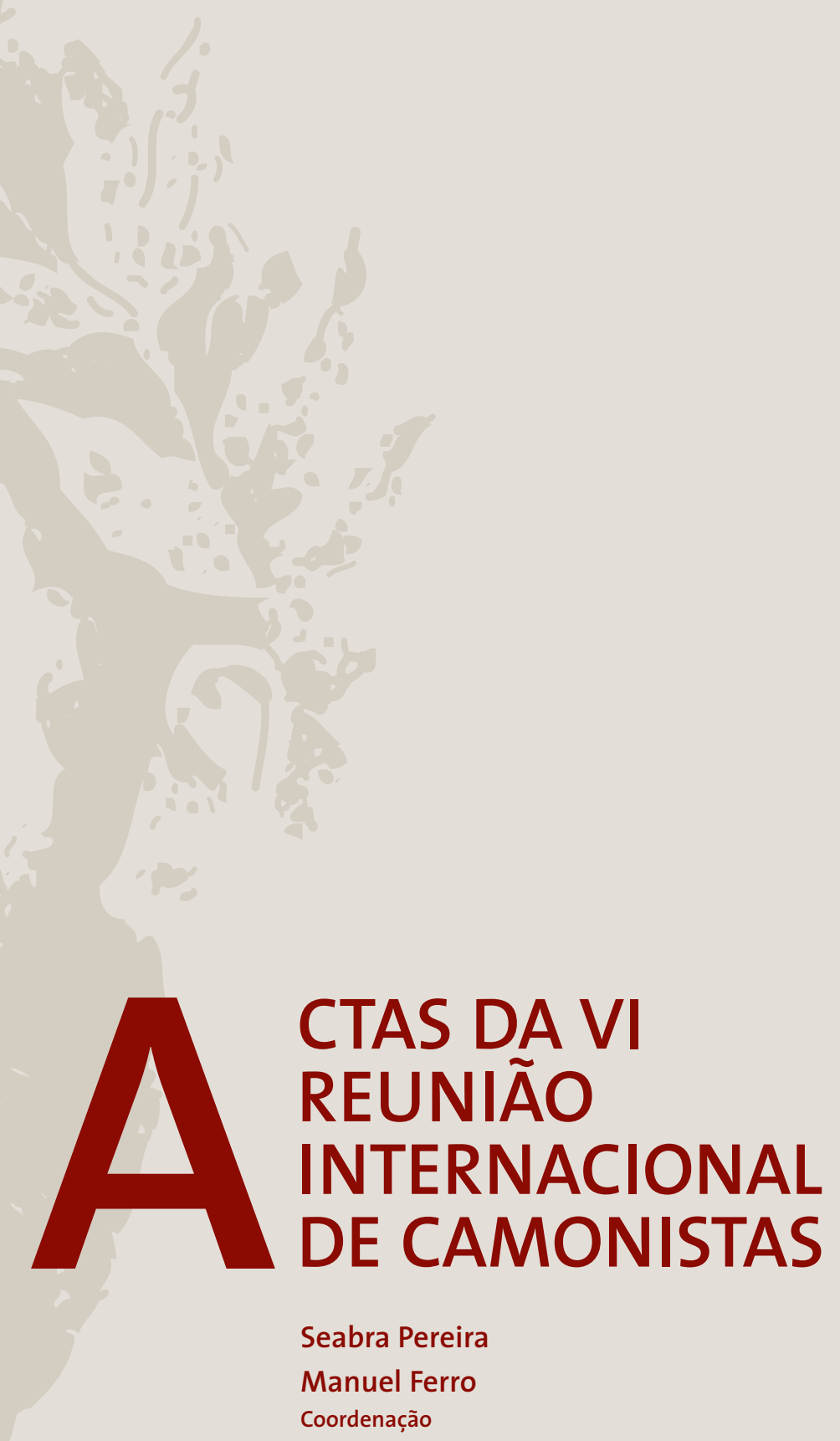


Júlia Garraio

Universidade de Würzburg

\section{A FIGURA DE CATARINA DE ATAÍdE NA PEÇA RADIOFÓNICA DE GÜNTER EICH DIE BRANDUNG VOR SETUBAL E NA NOVELA TOD DES DICHTERS DE LUDWING TIECK}

Em 1956 surgiu, na Alemanha, a peça radiofónica de Günter Eich Die Brandung vor Setubal ${ }^{1}$ (Diante de Setúbal, a ressaca ${ }^{2}$ ), que retoma a história dos amores lendários entre Luís Vaz de Camóes e Catarina de Ataíde. Segundo a lenda, o poeta, oriundo da baixa nobreza, ter-se-ia apaixonado por Catarina de Ataíde, dama da rainha e membro de uma das mais poderosas famílias do reino. A ela terá Camóes dedicado uma série de poemas, onde a amada figura sob o anagrama de Natércia. O desfecho destes amores revelar-se-ia, porém, fatídico: o poeta terá tido de enfrentar um rival em duelo, abandonar a corte e passar dezassete anos desterrado em África e na Ásia, enquanto a amada viria a falecer muito jovem. Neste século, a investigação histórica aponta outras razóes para o exílio de Camóes, pondo em causa até a veracidade da história de amor infeliz, por inexistência de elementos comprovativos (cf. Saraiva, Lopes, 1987, pp. 323-324). Apesar disso, este episódio corresponde a um dos momentos mais conhecidos da vida do poeta, tendo marcado, de forma decisiva, a literatura e bibliografia camonianas.

Ao longo dos séculos, a vida de Camóes serviu de inspiração para numerosas obras de ficção, tanto no espaço português, como no estrangeiro. Juntamente com o terramoto de Lisboa, em 1755, e a lenda de Inês de Castro, corresponde a um dos temas portugueses que gozou de uma recepção mais frutífera e notável na literatura universal. $\mathrm{O}$ auge deste entusiasmo pela personalidade e pelo destino trágico de Camóes ocorreu durante o Romantismo, tendo o espaço alemão sido palco de uma recepção muito fértil da obra camoniana, a par do surgimento de vários textos literários baseados em episódios da vida do poeta português. A figura de Catarina de Ataíde está presente na maioria destas obras, ocupando o papel da amada bela e sensível, pertencente à alta aristocracia e, desta maneira, inatingível para o poeta. O sofrimento amoroso, além de dar um rumo trágico à vida de Camóes, funciona também como uma fonte de inspiração artística, que leva algum conforto e consolo à sua existência solitária.

\footnotetext{
${ }^{1}$ Esta obra será referida através da sigla BS seguida do respectivo número da página.

2 Tradução de Ilse Losa e Marta Cristina de Araújo, publicada em 1970 na revista Humboldt. Esta obra será referida através da sigla $S$ seguida do respectivo número da página.
} 
Os escritores que, no espaço alemão, durante o Romantismo ou sob a sua influência, escreveram obras literárias sobre Camóes, foram, na sua grande maioria, há muito já esquecidos: Wilhelm Chezy, Uffo Horn, Hermann Theodor von Schmid, Moritz Hartmann, Friedrich von Schack. Apenas a novela de Ludwig Tieck, Tod des Dichters ("Morte do Poeta") (1834), e o drama em um acto de Friedrich Halm, Camoens (1837), despertam ainda algum interesse na Germanística. A maioria destas obras sobre a figura do épico português pertence à chamada "Künstlerdichtung" - literatura do artista -, um tipo de ficção que se tornou moda na primeira metade do século XIX e tematiza a personalidade e a função do poeta na sociedade. Como génio, este está condenado ao fracasso, à solidão, a ser desprezado e expulso de um mundo onde não há lugar para ideais e apenas o poder do dinheiro reina (cf. Wilmsmeier, 1913, pp. 1-10). Camóes tornou-se um mito no Romantismo Alemão, uma vez que a geração intelectual da época viu espelhada na existência do poeta português a concretização do topos romântico do artista genial pré-destinado, não reconhecido pelos seus contemporâneos, incapaz de atingir e realizar os sonhos e desejos pessoais de plenitude amorosa.

No século XX, além do ensaio histórico de Reinhold Schneider, Das Leiden des Camoens oder Untergang und Vollendung der portugiesischen Macht ("Os sofrimentos de Camóes ou decadência e apogeu do poder português”) (1930), surgiu apenas uma obra, na Alemanha, que utiliza como ponto de partida a temática camoniana - a peça radiofónica de Günter Eich Die Brandung vor Setubal. Catarina de Ataíde, e não Camôes, é aqui a figura principal. Devido à relação amorosa com o poeta, encontrase há quase trinta anos desterrada em Setúbal. Velha e marcada pela dependência alcoólica vive num mundo próprio, quase irreal, cujo símbolo é uma ressaca que somente ela ouve. A crença de Catarina na imortalidade do seu nome, através da poesia de Camóes - onde, sob o anagrama Natércia, figura como a amada desejada - será posta em causa, por um lado, através da visão dura dos criados e, por outro, pela sua própria incapacidade de encontrar paz espiritual numa existência monótona e sem perspectivas. Uma chávena trocada leva-a a questionar toda a sua vida até aí, especialmente a notícia da morte do poeta, dez anos antes, como vítima da peste. Ao longo da viagem até Lisboa, que entấo efectua para o procurar, encontra um estalajadeiro - antigo companheiro de armas de Camóes na Índia - o criado Ojau e Dona Antónia, mãe do poeta. Catarina considera falsos os relatos destas personagens, até mesmo a advertência de uma nova epidemia em Lisboa. Segundo ela, Camóes ainda vive, mas esconde-se, propositadamente, por ela se ter tornado feia e velha. Quando vai até ao palácio real, para exigir do rei a beleza e a juventude perdidas, encontra apenas um caixão - também o monarca morrera vítima da peste. Entretanto o criado Pedro foge com as riquezas, mas Rosita decide voltar com a sua senhora para Setúbal. Enquanto atravessam o Tejo, de barco, Catarina despede-se da cidade da sua juventude e descobre que também ela está contagiada. No entanto, parece feliz, pois sente que a peste lhe confirma a morte e o amor do poeta.

Este resumo da peça mostra que Eich procedeu a um tratamento livre da lenda, especialmente na figura de Catarina, a bela jovem do mito camoniano. Póem-se aqui necessariamente algumas questóes: quando e como Eich tomou conhecimento com esta temática; e por que razão a mudou de tal maneira. Segundo Joachim Storck, o escritor teria descoberto o tema durante a sua estadia em Portugal, em 1955 (cf. Storck, 1988, p. 51). A alusão a Camóes e à sua epopeia Os Lusíadas, na peça 
radiofónica Das Jahr Lazertis (1952), atesta, no entanto, um interesse pelo poeta português anterior à referida viagem. Além disso, não há provas de que Günter Eich dispusesse de conhecimentos suficientes da língua portuguesa que lhe possibilitassem consultar documentos históricos e obras literárias em Portugal. As duas mudanças mais radicais na peça são a apresentação de Catarina como anciã desterrada em Setúbal, sobrevivendo a Camóes, e as dúvidas em relaçáo à morte do poeta. Estes traços não se encontram em nenhum estudo português, mas aparecem numa das mais conhecidas obras ficcionais alemãs que foram escritas sobre a vida de Camóes: a novela de Ludwig Tieck, Tod des Dichters. É bastante improvável que se trate de uma mera coincidência, especialmente se se tiver em conta que Eich possuía conhecimentos profundos sobre o Romantismo Alemão, tendo adaptado para a rádio obras de Eichendorff e do próprio Tieck ${ }^{3}$, bem como alguns contos fantásticos dos irmãos Grimm (cf. Cuomo, 1989, pp. 29-46). Na bibliografia crítica sobre o escritor, é frequentemente acentuada a forte influência que o Romantismo exerceu na sua produção literária (cf. Goodbody, 1988, pp. 252-362). É-se levado a crer, portanto, que as fontes utilizadas por Eich para a peça radiofónica teriam sido a novela de Tieck ou, talvez, também uma outra obra alemá que se tenha debruçado sobre a vida e a obra do poeta português: por exemplo, os estudos de Wilhem Storck ou o de Wilmsmeier, sobre a recepção camoniana na Alemanha.

A acção de Tod des Dichters decorre desde a preparação da cruzada para Alcácer-Quibir até à morte do rei Dom Sebastiâo. Catarina de Ataíde, após uma existência infeliz e solitária, devido à relação fatídica com Camóes, volta a encontrar alguma alegria na velhice através da companhia da neta, filha do fruto dos antigos amores com o poeta. Pelo reino cresce a popularidade da epopeia camoniana, enquanto se espalha a notícia da morte do seu autor dois anos antes. Catarina, no entanto, nutre ainda esperanças em voltar a vê-lo, incumbindo, por isso, o fiel criado Domingos de o procurar pelas ruas de Lisboa. De facto, ele ainda vive, mas pretende manterse afastado dos homens para evitar sofrer mais desilusóes e abandonos. No final da novela, o acaso possibilita um reencontro dos amantes, morrendo Camóes, feliz, nos braços daquela que sempre amou. Embora surja como anciâ, Catarina enquadra-se perfeitamente no papel de amada do mito camoniano - espelha a beleza da juventude e é por todos respeitada e admirada. Uma vida de dor e sofrimento causados por um amor contrariado, cujo valor ela nunca póe em causa, torna-a uma personagem trágica e muito idealizada. A crença em Deus, na pátria e na poesia do amado dá-lhe força para não temer a morte e aceitá-la como libertação e transição.

$\mathrm{Na}$ peça radiofónica Die Brandung vor Setubal, Eich joga com duas imagens de Catarina de Ataíde. Nas recordaçóes desta personagem e da mãe de Camóes, bem como no soneto do poeta dedicado a Natércia, é apresentada uma amada bela e idealizada, cuja infelicidade foi desencadeada por uma história de amor platónico contrariado, com consequências fatídicas. Esta imagem, que apenas pertence ao passado e à poesia, corresponde à concepção romântica da figura. Na vida de Camóes, Catarina desempenha um papel ambivalente, sendo, por um lado, a causa do seu sofrimento e

\footnotetext{
${ }^{3}$ Em 1935, Eich adaptou para a rádio a novela de Tieck Des Lebens Überfluß. O texto desapareceu (cf. Cuomo, 1989, p. 35).
} 
desterro. Dona Antónia, a mãe do poeta, responsabiliza-a por toda as desgraças que acompanharam a vida do filho:

"Mutter: Dann hat er ein Duell gehabt, auch Ihretwegen. An Allem sind Sie schuld. Indien, China, Madagaskar, eine Flintenkugel ins linke Aug, Gefängnis, Verbannung, - alles Ihre Schuld! Wenn ich nur besser sehen könnte, - ich möchte mir wirklich diese rothaarige Person genau ansehen, die ihn so zugrunde gerichtet hat." (BS., p. 363)

[Máe: Depois, teve um duelo por sua causa. A senhora é culpada de tudo: Índia, China, Madagáscar, uma bala no olho esquerdo, prisão, desterro ${ }^{4}$ - é culpada de tudo! Se eu tivesse melhor vista, muito gostava de examinar essa ruiva que o arruinou!] (S, p. 81)

Mas, ao mesmo tempo, também foi Catarina quem deu a Camóes a inspiração para os sonetos que o tornaram o maior poeta português. Numa conversa com Rosita, a protagonista revela bastante orgulho pela fama poética do amado, enquanto a criada, possuídora de um espírito mais realista, a adverte sobre as consequências funestas e solidão que esses mesmos poemas trouxeram para o destino da sua senhora. A união inevitável entre o dom para a criação artística e a incapacidade de atingir a felicidade na vida real, um motivo muito caro aos românticos, é, desta maneira, reactualizada na peça.

Rosita: Und wenn er die Gedichte für sich behalten hätte?

Catarina: Rosita! Wäre er dann der größte Dichter Portugals geworden? Säßen wir dann hier und sprächen von ihm?

Rosita: Nein, aber Sie hätten vielleicht Kinder und Enkel.” (BS, p. 334)

[Rosita: E se ele tivesse guardado os poemas?

Catarina: Nesse caso não se teria transformado no maior poeta de Portugal? Estaríamos nós aqui a falar dele?

Rosita: Não, mas talvez a senhora tivesse filhos e netos.] (S., p. 73)

Por outro lado, ao longo da peça radiofónica encontramos uma Catarina totalmente diferente, cuja existência enfadonha, solitária, absurda e sem sentido, cuja dependência do álcool, obsessóes e afastamento da realidade não deixam ver qualquer vestígio da beleza do passado romântico. Pedro, um criado bronco e sem escrúpulos, numa conversa com a amante, refere-se à sua senhora em termos insultuosos, designando-a por "espantalho a cheirar a vinho tinto» (cf. S., p. 74).

A tentativa infrutífera da protagonista em encontrar consolo na poesia de Camóes torna-se bastante clara no momento em que ordena à criada Rosita que recite um soneto. Visto esta nada entender de poesia e da temática do soneto em causa, Catarina

\footnotetext{
${ }^{4}$ Procedi, neste ponto, a uma adaptação da tradução que ignorou as seguintes palavras do original, “Gefängnis" (prisão) e "Verbannung” (desterro).
} 
comporta-se como um encenador (cf. S., pp. 72-73). A seriedade do tema - a dor do poeta por estar afastado da amada - vai ser destruída e parodiada ao longo da representação, tornando-se uma cena cómica aquela que deveria mostrar o sofrimento da personagem principal. $\mathrm{O}$ conteúdo do soneto é também posto em causa pelo presente de Catarina, uma vez que a queixa, sobre os sete dias em que o poeta teve de permanecer longe da amada, perde a força e parece quase uma dor fictícia, se se tiver em conta a solidão da própria protagonista ao longo de trinta anos, além disso, a definição que esta dá de poesia lírica como uma espécie de jogo com a forma e as palavras, que transcende os sentimentos, opóe-se à apresentação da realidade palpável:

"Catarina: Die menschliche Gesittung nämlich beginnt, wenn sich das Geschöpf Gottes über die Bloße rohe Natur erhebt. Was sind doch Gefühle! Da reibt sich Haut an Haut, das haben die Stallmägde und die Müllerburschen auch. Erst wenn die Gefühle sich reimen, Rosita, das ist etwas.” (BS., p. 333)

[Catarina: A sensibilidade começa quando a criatura de Deus transpóe a natureza. O que são, na verdade, os sentimentos? Uma pele a roçar outra pele? Isso fazem-nos os camponeses e os moços de moleiro. Só quando se rimam os sentimentos é que se conhece a sua verdadeira qualidade.] (S., p. 73)

É notável a discrepância entre esta definição e a lírica de Eich dos anos cinquenta e sessenta, caracterizada por uma temática absurda e abstracta, bem como pelo desrespeito das normas tradicionais da lírica (cf. Neumann, 1981). As seguintes notas do espólio do escritor, referente aos anos de 1947/48, acentuam a sua desconfiança em relação ao soneto e a todas as normas literárias, entendidas como uma espécie de fraude.

"Die Vorliebe für das Sonett: Rückzug in erprobte Ordnungen. Angst, die gleiche, der die CSU ihre Stimmen verdankt. Bedürfnis, das Gleichgewcht, den status quo zu halten. Ferte Formen täuschen ein Gefühl von Sicherheit vor. Rüstung, die einen schlotternden Körper hält.” (apud. Storck, 1988: 39)

[A preferência pelo soneto equivale a um recuo para regras já experimentadas. O medo, o mesmo a que a CSU agradece os seus votos. Necessidade de manter o equilíbrio, o statu quo. Formas fixas iludem, dando uma sensação de segurança. Armação que mantém um corpo cambaleante.]

Daqui podemos concluir que, por detrás da apresentação de um soneto de Camóes ${ }^{5}$, existem intençôes parodísticas. Eich tematiza, assim, a essência, fictícia e estranha à realidade, da lírica amorosa tradicional, que a torna incapaz de desempenhar um papel real no mundo.

A solidão e o sofrimento de Catarina podem despertar compaixão, aliás mais do que na novela de Tieck, onde a personagem gozava do amor e do respeito da família, da dedicaçáo do criado, e ainda encontrava consolo na poesia de Camóes e na religiáo.

\footnotetext{
${ }^{5}$ O próprio Eich escreveu o soneto (cf. Funke, 1965, p. 69).
} 
$\mathrm{Na}$ peça radiofónica a sua solidão é extrema - nenhum familiar a acompanha após o desterro; os criados consideram-na louca. Paralelamente, a sua actuação e as suas afirmaçôes são, frequentemente, ridículas e desprovidas de sentido, tornando-se, assim, a velha e real Catarina uma caricatura da sua própria crença, onde figura como amada romântica. A protagonista é duramente obrigada a encarar e reconhecer a destruição desse seu mundo interior, belo e cheio de encanto, ao descobrir como a poesia tinha sofrido uma banalização extrema: através da popularidade dos sonetos camonianos, o nome Natércia tornou-se de tal maneira uma moda que é esse o nome da burra do estalajadeiro, na peça. Catarina é uma personagem trágico-cómica exemplar, que se aproxima notoriamente das figuras do teatro do absurdo de Samuel Beckett. Ao longo da peça concretiza-se, desta maneira, a desmitificação, por um lado, dos amores lendários entre Camóes e Catarina de Ataíde e, por outro, do motivo tradicional da amada sensível e trágica, segundo a tradição romântica.

A figura de Catarina de Ataíde denota também a forte influência do existencialismo francês na literatura alemã do após-guerra. A solidão ${ }^{6}$ e o desterro da personagem são uma espécie de prisão, significando a viagem a Lisboa, no rasto de Camóes, uma procura do sentido do exílio e do amor infeliz que marcaram a sua vida. Trata-se de uma viagem de reconhecimento, durante a qual irá enfrentar as próprias ilusóes. Quando a protagonista se apercebe de que o seu desterro e a sua vida tinham sido esquecidos há muito, podendo, por isso, ter regressado muito antes a Lisboa, entende como o sofrimento e o exílio perderam o sentido. Se não tivesse considerado o próprio destino tão importante, Catarina ainda poderia ter levado uma vida normal e, talvez, ter encontrado o amado com vida. O resultado da procura da protagonista será a morte, a única certeza que encontra. Desde o início da viagem, pairam duas ameaças por ela ignoradas: o roubo e a peste em Lisboa. O motivo da vida em perigo é uma constante da literatura alemã dos anos 50, sob a influência do existencialismo, ligando-se a causas históricas muito concretas - o trauma da Segunda Guerra Mundial, a corrida ao rearmamento, a "guerra fria" - que levaram ao alastrar de um clima de insegurança e medo do possível rebentar de possível guerra nuclear e consequente fim do mundo. Logo desde o começo da peça radiofónica que as insinuaçôes da morte estão claramente presentes. A pensão onde os viajantes pernoitam é comparada a um caixão (cf. S., p. 75), sendo também o palco da cena em que Catarina ouve o zurro da burra Natércia e compreende, pela primeira vez, que todos têm de morrer (cf. S., p. 79). Palavras como "morte", "caixão" e a expressão "observar a ponta dos dedos" (os primeiros sinais da peste manifestavam-se na ponta dos dedos) formam uma isotopia na peça radiofónica, que deixa antever a proximidade da morte da protagonista, no final. Quando Catarina atinge o auge da sua viagem, nomeadamente a audiência com o rei, encontra um caixáo (cf. S., pp. 82-83). Ela desejava que o monarca lhe restituísse a juventude; no entanto, isto implicaria mudar o tempo, ou antes, libertar-se da inevitabilidade do decorrer do tempo e da chegada da morte. Tais dádivas apenas poderiam ser concedidas por um

${ }^{6}$ Dona Catarina espelha também uma situação real do após-guerra, nomeadamente a das viúvas de soldados caídos ou desaparecidos - isto é, mulheres incapazes de recomeçar uma vida por se encontrarem presas a recordaçóes do passado, procurando qualquer vestígio que lhes desse uma esperança na vida do ente desaparecido. 
deus. Mas o "seu Deus" - o rei - é também uma vítima da peste e, consequentemente, do tempo e dessa mesma morte. Deveremos entender este passo, na peça, como uma expressão da morte de Deus, do desamparo e da solidão humana no mundo? Catarina é contaminada pela epidemia e tem de encarar o próprio fim iminente, já iminente. Depois de ter perdido o consolo romântico - a poesia, o amor e Deus - ela afirma que a peste lhe devolveu o amor de Camóes:

"Catarina: (...) Seitdem ich die Pest habe, wei $\beta$ ich, da $\beta$ es die Pest gibt. Und $\mathrm{da}$ es die Pest gibt, gibt es auch das andere (...) Da es wahr ist, da $\beta$ Camóes gestorben ist, so ist es auch wahr, da $\beta$ er nach mir verlangt hat. Seine Liebe, das ist die Wahrheit, und die Pest hat sie mir zurückgegeben. Welch Schöner Zirkel, würdig den Bahnen des Mondes und der Sonne! Siech mich an, Rosita: Die Pest gab mir die Jugend zurück. Dem König sei gedankt.” (BS., pp. 373-374)

[Catarina: (...) tenho a peste, sei que a peste existe. E, como a peste existe, existe também o resto (...) Tâo verdadeiro como Camóes ter morrido e ter-me desejado. O seu amor é a verdade, a peste mo devolveu. Que belo círculo para servir de órbita à lua e ao sol. Olha bem para mim, Rosita! A peste restitui-me a juventude. Que o rei seja louvado.] (S., p. 84)

Assim se explica, na peça radiofónica, o subtítulo "Daran glauben müssen”. Esta expressão tem, na língua alemá, dois significados: por um lado, refere a necessidade humana de acreditar em algo, para encontrar um sentido na vida; por outro, a inevitabilidade de morrer. Segundo o crítico Horst Günter Funke, Catarina teve de entrar no limiar da morte para acreditar no falecimento do poeta e, assim, conseguir encontrar um sentido para a sua vida. Só neste momento pôde aceitar a própria existência e o fim iminente, regressando então a Setúbal, referido finalmente como lar (“daheim”) e já não como exílio (cf. Fuke, 1965, pp. 64-65). Nessa cidade, a ressaca, símbolo do seu afastamento da realidade, aguarda-a, porém, de novo. A meu ver, o fim da peça radiofónica surge como extremamente ambíguo: a protagonista viaja para Setúbal, montada na burra Natércia. Mostra esta imagem que ela superou verdadeiramente o medo da morte, reconheceu e perdeu por fim as ilusóes? $\mathrm{Ou}$ trata-se apenas de uma imagem das ilusóes e tolices humanas? O regresso a Setúbal parece-me ser apenas uma tentativa desesperada de, perante a morte, encontrar um sentido para uma vida que o não teve. Catarina nunca encontrou uma prova que lhe assegurasse, definitivamente, o destino de Camôes. A aproximação da própria morte é que a deixa aceitar o falecimento do amado, abandonando então a esperança de o voltar a encontrar. Ao mesmo tempo, no entanto, deixa-se prender por uma nova ilusão - a ilusão de que o poeta a teria amado até ao fim, apesar de também aqui nenhuma prova certificar esta crença. Tal pode significar que o homem se liberta de uma ilusão para, inevitavelmente, cair numa outra, pois é parte integrante da natureza humana a necessidade de acreditar em algo ("daran glauben müssen») para assim se conseguir aceitar a vida, sempre ensombrada pela presença da morte.

A desmitificação dos amores lendários entre Camóes e Catarina de Ataíde, em Die Brandung vor Setubal, está em concordância com novas tendências na obra de Günter Eich. O escritor começou a escrever, nos anos trinta, lírica da natureza e 
peças radiofónicas, sob a influência do Romantismo Alemão (cf. Goodbody, 1988, pp. 252-362). No após-guerra, e especialmente nos anos 60, afasta-se gradualmente da sua obra da primeira fase e da tradição literária ocidental. $\mathrm{Na}$ peça radiofónica Die Brandung vor Setubal, Eich estabelece uma relação intertextual com uma obra conhecida do Romantismo Alemão - Tod des Dichters - para pôr em causa os seus valores, ou, pelo menos, para mostrar a sua desadaptação à sociedade moderna. Poesia, religião e pátria não conseguem, na peça, consolar Catarina e libertá-la de um presente sem sentido e da morte. A fuga para o reino da poesia e dos ideais, no qual a protagonista surge como amada bela e desejada, é apresentada como loucura e negação da realidade, sendo a poesia amorosa, consequentemente, algo ilusório e fictício. Eich afasta-se desta maneira, claramente, das influências do Romantismo e da sua produção literária anterior.

Segundo Michael Oppermann, Die Brandung vor Setubal sinaliza uma mudança na obra de Eich, ao abrir a última fase da sua produção literária. A realidade interior (o sonho, a fantasia e a recordaçáo) que, nas obras anteriores do escritor, aparecia como um refúgio possível do mundo cruel, é aqui posta em causa e, até mesmo, insinuada como loucura (cf. Oppermann, 1990, p. 134). A última fase da produção eichiana (a partir dos anos 60) é caracterizada, segundo a bibliografia crítica, pelo abandono da valorização da realidade interior, pelo uso de técnicas do teatro do absurdo e pela tematização das dúvidas crescentes do escritor em relação à capacidade de a linguagem humana e a literatura serem capazes de revelar e modificar a realidade. Embora numa fase ainda germinal, estes aspectos podem ser facilmente detectados na peça radiofónica do escritor, de 1956, Die Brandung vor Setubal. 